\title{
Social networks and obesity among Somali immigrants and refugees
}

Jane W. Njeru*, Mark L. Wieland ${ }^{1}$, Janet M. Okamoto², Paul J. Novotny ${ }^{3}$, Margaret K. Breen-Lyles ${ }^{4}$, Ahmed Osman $^{5}$, Yahye A. Ahmed', Mohamud A. Nur ${ }^{1}$, Omar Nur $^{6}$ and Irene G. Sia ${ }^{1}$

\begin{abstract}
Background: Somali immigrants and refugees to the United States are at high risk for obesity and related cardiovascular risk. Social network factors influence health behaviors and are important contributors to the obesity epidemic. The objective of this study was to describe social networks and obesity-related characteristics among adult Somali immigrants in a Minnesota city in order to inform a community-based, participatory, research-derived, social network intervention to decrease obesity rates.
\end{abstract}

Methods: Survey data (demographics, general health measures, and sociobehavioral and network measures) and height and weight measures (for calculating body mass index) were collected from adult Somali immigrants by bilingual study team members at community locations. Descriptive statistics were used to report the survey and biometric data. Logistic regression models were used to describe the basic associations of participants and network factors. Network data were analyzed to identify nodes and ties, to visualize the network, and to identify potential interventionists for a future social network intervention.

Results: Of the 646 participants, 50\% were overweight or affected by obesity. The network had 1703 nodes with 3583 ties between nodes, and modularity was high (0.75). Compared with respondents of normal weight, participants who were overweight or affected by obesity had more network members who were also overweight or obese (odds ratio $[\mathrm{OR}], 2.90 ; 95 \% \mathrm{Cl}, 1.11-7.56 ; P=.03)$; this was most notable for men $(\mathrm{OR}, 4.58 ; 95 \% \mathrm{Cl}, 1.22-$ $17.22 ; P=.02)$ and suggestive for those 50 years or older $(\mathrm{OR}, 24.23 ; 95 \% \mathrm{Cl}, 1.55-377.83 ; P=.03)$. Weight loss intention among participants who were overweight or affected by obesity was associated with number of family members and friends trying to lose weight, enabling functional network factors (social norms for weight loss, social support for healthy eating, and social cohesion), and less favorable obesogenic social norms.

Conclusions: In this community sample of Somali immigrants, distinct social networks are clustered by weight status, and social contacts and functional network characteristics are related to individuals' weight loss intentions. These factors should be considered in weight loss interventions and programs. A social network intervention targeting weight loss, within a community-based participatory research framework, is feasible in this vulnerable population.

Keywords: Community-based participatory research, Immigrants, Obesity, Refugees, Social network analysis, Somali

\footnotetext{
* Correspondence: Njeru.Jane@mayo.edu

${ }^{1}$ Department of Medicine, Mayo Clinic, Rochester, MN, USA

Full list of author information is available at the end of the article
}

(c) The Author(s). 2020 Open Access This article is distributed under the terms of the Creative Commons Attribution 4.0 International License (http://creativecommons.org/licenses/by/4.0/), which permits unrestricted use, distribution, and reproduction in any medium, provided you give appropriate credit to the original author(s) and the source, provide a link to the Creative Commons license, and indicate if changes were made. The Creative Commons Public Domain Dedication waiver (http://creativecommons.org/publicdomain/zero/1.0/) applies to the data made available in this article, unless otherwise stated. 


\section{Background}

In the early 1990s, after the outbreak of civil war in their country, Somali refugees began arriving in the United States (US) [1, 2]. They constitute the largest group of refugees from sub-Saharan Africa in the US and a sizable proportion of immigrants from Africa, with their numbers doubling in each of the past 3 decades [3, 4]. Forty percent of Somali refugees settled in Minnesota, where they compose the majority of the $21 \%$ of the state's foreign-born population that is from Africa [5].

Somali immigrants and refugees in the US and other Western countries have disproportionately higher rates of obesity and related cardiovascular disease risks, such as diabetes mellitus [6-12]. The higher rates have been postulated to result from the adoption of lifestyles that include low levels of physical activity and a diet rich in refined carbohydrates and fat $[10,13,14]$. In turn, these lifestyle and behavioral factors that promote the development of obesity are enabled by multiple, complex, and interconnected social and environmental factors $[15,16]$. To effectively address this obesity epidemic, interventions that take into account the social context of individuals and communities need to be explored.

Within the general population, social network structures have been identified as contributors to the obesity epidemic $[17,18]$, in part, through transmission of obesogenic behaviors [19]. It is postulated that structural and functional characteristics of groups (eg, social networks) influence behaviors through several pathways. Structural network factors, such as size, density, and composition, may affect obesity-related behavior through normative self-comparison and thereby direct the influence of peers (among other factors), leading to adoption of similar behaviors. Functional network factors, in contrast, may influence obesity-related behavior through shared social activities, social norms, social cohesion, and social support [20]. The potential role of social network structures in the obesity crisis has been demonstrated in certain immigrant populations, including Hispanic and Eastern European immigrants [21], but not among immigrants and refugees from sub-Saharan Africa.

Social network interventions involve purposeful use of existing social networks in the natural environment to promote positive behavior change and health outcomes [22], and they have been associated with consistent findings of positive behavior change [23]. The understanding of network factors within different populations at risk for obesity (eg, Somali) is an important step toward derivation of a network intervention aimed at attenuating this risk.

Like other minority groups in the US, refugee and immigrant populations are hard to reach through traditional research and intervention pathways, and they may not easily adapt to existing community-based programs and resources [24]. In community-based participatory research (CBPR), community members and academics partner in an equitable relationship through all phases of research and intervention development. CBPR is well suited to address the interplay between behaviors and social determinants of health $[25,26]$, and it has been an effective means of approaching health topics among immigrant and refugee populations [27].

Rochester Healthy Community Partnership (RHCP) is a CBPR partnership whose mission is "to promote health and well-being among the city population through communitybased participatory research, education, and civic engagement to achieve good health for all" [19]. RHCP was conceived in 2004 and has been effective in designing and implementing several interventions with immigrant and refugee populations in Rochester, Minnesota [28-30]. In the Healthy Immigrant Families (HIF) randomized controlled trial, RHCP community and academic partners developed and tested a healthy eating and physical activity intervention among Somali families [28]. The adults in the participating families had significant improvement in dietary quality. Subsequently, through diffusion of the intervention through word of mouth in the community, the RHCP partners conceived of a possible social network intervention, through which a version of the healthy eating and physical activity intervention used in HIF could be modified to be delivered by peer interventionists within the social networks. As a first step, a social network analysis needed to be conducted, and obesity-related network characteristics among Somali refugees and immigrants in the community needed to be described.

The hypotheses of the present study were 1) that an association exists between the weight status of study participants and that of persons in their social network; 2) that for participants who are overweight or obese, an association exists between their weight loss intentions and the intentions of persons in their social networks; and 3) that social norms for weight loss, social support for healthy behaviors, and social cohesion would mediate the relationship between participants weight loss intentions and their social network. The overall goals of this study were 1) to elucidate social networks among Somali immigrants and refugees in Rochester, Minnesota; 2) to describe obesityrelated network characteristics; and 3) to identify peer leaders as potential future interventionists within networks. This work will form the foundation of a CBPRderived social network intervention for nutrition and physical activity that targets behavior change to decrease obesity rates and cardiovascular risk among community members who are overweight or affected by obesity.

\section{Methods}

Study setting and participants

This study was conducted in a participatory manner, consistent with CBPR norms, by RHCP members and 
academic and community partners from the Somali community. Participant recruitment was limited to selfidentified Somali community members living in Rochester, Minnesota, and the surrounding areas. All study procedures were approved by the Mayo Clinic Institutional Review Board.

\section{Data collection}

The survey was administered by 3 bilingual RHCP community partners and study team members. It was entirely community placed, and various practical approaches were used in recruitment through nonprobability snowball sampling. Possible participants were approached in various social gathering places, including places of worship, sporting events, offices, homes, restaurants, and schools. Besides using existing community events, the community partners also organized small gatherings and meetings solely for recruitment for this study. Data were collected at recruitment or at another prearranged time at the convenience of the study participants.

\section{Data collection instruments}

Data collection instruments were prepared by academic and community partners from the Somali community. Survey items were obtained from existing validated instruments. Most instruments did not previously exist in the Somali language. These items were edited by RHCP partners, adapting the World Health Organization's translation procedure for use with survey instruments in a CBPR framework [31]. This multistep process includes the following: forward translation, panel discussion, backward translation, pretesting, cognitive briefing, and a consensus on the final instrument by a core group of Somali community partners [32].

\section{Demographic, biometric, and health behavior measures}

Demographic information collected through a survey included the following: age, sex, ethnicity, country of birth, annual household income, education level, employment status, number of years lived in the US, primary language spoken at home, and level of English language proficiency on a 4-point Likert scale.

Weight was measured to the nearest $0.1 \mathrm{~kg}$ with a portable digital floor scale. Height was measured to the nearest $0.1 \mathrm{~cm}$ with a stadiometer. Body mass index (BMI) was calculated as weight in kilograms divided by height in meters squared. For each participant, data on dietary behaviors were obtained with a dietary screener of 7 items adapted from the food behavior checklist [33]. The food behavior checklist questions include color images of vegetables (fresh and cooked) and fruits that depict a serving size Physical activity was assessed with the International Physical Activity Questionnaire (IPAQ), and calculated per a pre-specified protocol to define three activity levels (https://sites.google. com/site/theipaq/scoring-protocol) [34].

\section{Network measures and characteristics Structural networks measures}

Egocentric, or personal network, data were collected from each survey participant to address the hypotheses of the study. To identify network members, participants were asked to name up to 10 members of their social network (ie, their discussion network). Names and phone numbers were collected for each alter (ie, network member) to verify identities because of the similarity in names among members of the Somali community. For network members without survey data, perceived dietary quality and physical activity level for each named alter were collected from each participant. The weight status of each named alter was described on a 4-point scale (underweight, normal weight, overweight, or very overweight) by the participant who identified the alter as a social tie (ie, connection). For the analysis, the overweight and very overweight groups were consolidated into 1 overweight group. If the network member was named by more than 1 survey respondent, consensus on overweight status was determined from the average of all reports (with 1 point assigned to "underweight" and 4 points to "very overweight"). The average number of overweight network members was calculated for each survey respondent who reported a network tie. The average was calculated as the number of overweight network members divided by the total number of reported ties.

Network size for each participant was calculated as the number of persons with whom a participant had a reported tie.

\section{Functional networks measures}

For all participants, social norms for obesity and obesityrelated behaviors were measured with a 3-item instrument to assess social acceptability of being overweight, eating an unhealthy diet, and being physically inactive, and were reported on a 5-point Likert scale (internal consistency, Cronbach $\alpha=0.69$ ) [35]. Social cohesion was measured with a 3-item measure to assess the "sense of belonging" construct and was reported on a 5-point Likert scale (reliability, Cronbach $\alpha=0.95$ ) [36].

Social support for eating a healthy diet was assessed with a 5-item instrument and reported on a 5-point Likert scale (internal consistency, Cronbach $\alpha=0.61-0.91$ ) [37].

For participants who were affected by obesity and those who were overweight only, the number of social contacts trying to lose weight was assessed on a 5-point scale from 0 (nobody) to 4 (all). Intention to lose weight in the next 3 months was assessed with a 1-item measure (How likely are you to try to lose weight within the next 3 months?) and reported on a 5-point likeness scale. Social norms for weight loss were obtained with a 3item instrument reported on a 5-point Likert scale (reliability, Cronbach $\alpha=0.70$ ) [35]. 
In this study, the social cohesion instrument demonstrated excellent internal consistency (Cronbach alpha 0.93 ) with individual item loading ranging from 0.89 to 0.94. The social norms for obesity instrument demonstrated good internal consistency (Cronbach alpha 0.85) with individual item loading ranging from 0.80 to 0.90 . The social support instrument demonstrated excellent internal consistency (Cronbach alpha 0.92) with individual item loading ranging from 0.84 to 0.89 . The social norms for weight loss instrument demonstrated fair internal consistency (Cronbach alpha 0.73) with individual item loading ranging from 0.68 to 0.85 . On bivariate analysis, social support was correlated with social norms for weight loss (correlation of $0.35, p<0.0001$ ), social cohesion (correlation of $0.22, p<0.0001$ ), and social norms for obesity (correlation of $-0.20, p<0.001$ ). There were no correlations between any of the other three functional network characteristics.

\section{Peer leader identification}

To identify potential peer interventionists, participants were asked to name the people that they go to most often when they need advice, including general advice and specific advice about diet, physical activity, and weight loss. They also named people that they and others respected as leaders in the community.

\section{Data analysis}

Descriptive statistics were used for demographic, biometric, and survey data. Logistic models were incorporated to assess the association between participant and network demographics with binary characteristics such as BMI status and weight loss intention. For estimation of causal mediation effects, the method described by VanderWeele was used [38]. Associations were assessed with logistic models with no adjustments for other covariates. Analyses were performed with SAS version 9.2 software (SAS Institute Inc) and, in particular, the SAS CAUSALMED procedure for mediation analysis.

Network data were analyzed to identify nodes and ties and to visualize the network. The study assessed participants' egocentric (ie, personal) networks. Network members were linked across individuals through matching names and phone numbers. A hybrid approach, of compiling egocentric network data to form a larger sociocentric network, was used to visualize this real-world community network. If the names and phone numbers of named network members did not match, the members were considered as different individuals in the analysis, so that any error would be an underestimate of position and importance in the overall network. Edgelists of egos and alters were created, and ego attribute data based on survey responses were compiled to import into network analytic software with Stata (StataCorp LLC)
[39]. UCINET (Analytic Technologies) [40], Gephi (Gephi Consortium) [41], and R (R Foundation) [42] were used to calculate network metrics (UCINET and Gephi), to conduct more complex network analysis (UCINET and R), and to visualize social networks (Gephi). Although a hybrid approach was used to build and visualize a larger community network, the measures used in the analysis were egocentric in nature (ie, percentage of personal network that is overweight).

\section{Results}

The survey and biometric measurements were completed by 646 participants. This number exceeded the recruitment goal of at least $30 \%$ of the Somali adults residing in Rochester, Minnesota, according to the 2007-2011 American Community Survey. Demographic characteristics are shown in the Table 1. The mean (SD) age was 37.5 (16.7) years; $45 \%$ of the participants were female; $69 \%$ of the participants had a high school education or less; and $75 \%$ reported an annual family income of less than $\$ 30,000$. Most (93\%) of the participants were born outside the US, and 65\% had limited proficiency with the English language. Participants 50 years or older had lived in the United States longer than younger participants (15.4 years vs 13.2 years, $P=.04$ ).

Half the participants were overweight or affected by obesity, and mean (SD) BMI was 26.4 (5.5). Among participants who were 50 years or older, BMI was significantly higher: mean (SD), 28.3 (5.1); $P<.001$. Among participants with a BMI of at least $25(n=328), 79 \%$ reported an intention to likely or very likely try to lose weight in the subsequent 3 months.

Among all participants, 62\% reported drinking regular soda at least sometimes, and $70 \%$ reported drinking fruit drinks, punch, or sports drinks at least sometimes. The mean (SD) number of daily servings of vegetables was 2.2 (1.7), and the mean (SD) number for fruit was 2.2 (1.8); $47 \%$ of respondents reported high physical activity level on the IPAQ.

\section{Network characteristics}

The network had 1703 nodes with 3583 ties between nodes. Figure 1 shows the network according to weight status. For the entire network sample, including all survey respondents and named alters $(N=1703)$, the percentage of the sample that was reported as overweight or affected by obesity was $26.7 \%$.

Mean (SD) network size was 5.7 (1.3). It was significantly smaller among participants 50 years or older $(5.5$ [1.2] vs 5.8 [1.3], $P<.001)$.

Social norms for obesity among the entire sample were low (mean [SD], 3.6 [3.2]), meaning that there was low acceptability of being overweight or affected by obesity, eating unhealthy food, or being physically inactive 
Table 1 Participant Demographics and Survey Responses $(N=646)^{a}$

\begin{tabular}{|c|c|c|c|}
\hline Measurement & Female $(N=278)$ & Male $(N=364)$ & Total $(N=646)$ \\
\hline Age, mean (SD), y & $39.4(16.2)$ & $36.0(17.0)$ & $37.5(16.7)$ \\
\hline \multicolumn{4}{|l|}{ Formal schooling completed, No. (\%) } \\
\hline$\leq 8$ grades & $124(45)$ & $41(11)$ & $165(26)$ \\
\hline Some high school & $23(8)$ & $41(11)$ & $64(10)$ \\
\hline High school or general equivalency diploma & $60(22)$ & $134(37)$ & $194(30)$ \\
\hline Some college or technical school & $49(18)$ & $98(27)$ & $147(23)$ \\
\hline College or advanced degree & $19(7)$ & $49(13)$ & $68(11)$ \\
\hline \multicolumn{4}{|l|}{ Annual family income, \$, No. (\%) } \\
\hline 0-9999 & $130(47)$ & $130(36)$ & $260(41)$ \\
\hline $10,000-19,999$ & $49(18)$ & $53(15)$ & $102(16)$ \\
\hline $20,000-29,000$ & $53(19)$ & $61(17)$ & $114(18)$ \\
\hline $30,000-49,999$ & $31(11)$ & $80(22)$ & $111(18)$ \\
\hline$\geq 50,000$ & $12(4)$ & $34(9)$ & $46(7)$ \\
\hline \multicolumn{4}{|l|}{ Health insurance in past $12 \mathrm{mo}$, No. (\%) } \\
\hline Yes & $263(95)$ & $313(86)$ & $576(90)$ \\
\hline No & $13(5)$ & $50(14)$ & $63(10)$ \\
\hline \multicolumn{4}{|l|}{ Country of birth, No. (\%) } \\
\hline United States & $14(5)$ & $31(9)$ & $45(7)$ \\
\hline Other & $255(595)$ & $319(91)$ & $574(93)$ \\
\hline \multicolumn{4}{|l|}{ English language proficiency, №. (\%) } \\
\hline Not at all & $34(13)$ & $22(6)$ & $56(9)$ \\
\hline Not very well & $94(35)$ & $59(16)$ & $153(24)$ \\
\hline Well & $72(26)$ & $121(34)$ & $193(31)$ \\
\hline Very well & $72(26)$ & $158(44)$ & $230(36)$ \\
\hline Body mass index, mean (SD) & $28.1(6.1)$ & $25.1(4.7)$ & $26.4(5.5)$ \\
\hline Normal weight (BMI $18.5<25$ ), No. (\%) & $97(35)$ & $211(59)$ & $308(49)$ \\
\hline Overweight (BMI 25 < 30), No. (\%) & $86(31)$ & $97(27)$ & $183(29)$ \\
\hline Obese, No. (\%) & $92(33)$ & $52(14)$ & $144(23)$ \\
\hline \multicolumn{4}{|l|}{ Dietary behaviors } \\
\hline \multicolumn{4}{|l|}{ Do you drink regular soda? No. (\%) } \\
\hline No & $134(49)$ & $106(29)$ & $240(38)$ \\
\hline Sometimes & $108(39)$ & $174(48)$ & $282(44)$ \\
\hline Often & $23(8)$ & $53(15)$ & $76(12)$ \\
\hline Every day & $11(4)$ & $29(8)$ & $40(6)$ \\
\hline \multicolumn{4}{|c|}{ Do you drink fruit drinks, punch, or sports drinks? No. (\%) } \\
\hline No & $122(44)$ & $67(19)$ & $189(30)$ \\
\hline Sometimes & $79(29)$ & $146(41)$ & $225(35)$ \\
\hline Often & $63(23)$ & $101(28)$ & $164(26)$ \\
\hline Every day & $13(5)$ & $46(13)$ & $59(9)$ \\
\hline No. of servings of vegetables daily, mean (SD) & $2.2(1.3)$ & $2.2(2.1)$ & $2.2(1.7)$ \\
\hline No. of servings of fruit daily, mean (SD) & $2.3(1.3)$ & $2.2(2.0)$ & $2.2(1.8)$ \\
\hline
\end{tabular}


Table 1 Participant Demographics and Survey Responses $(N=646)^{\mathrm{a}}$ (Continued)

\begin{tabular}{|c|c|c|c|}
\hline Measurement & Female $(N=278)$ & Male $(N=364)$ & Total $(N=646)$ \\
\hline \multicolumn{4}{|l|}{ Physical activity, ${ }^{\mathrm{b}}$ No. (\%) } \\
\hline Low & $71(26)$ & $48(14)$ & $119(19)$ \\
\hline Moderate & $109(40)$ & $104(29)$ & $213(34)$ \\
\hline High & $94(34)$ & $202(57)$ & $296(47)$ \\
\hline Self-efficacy for healthy diet, mean $(S D)^{c}$ & $4.2(0.9)$ & $3.9(1.0)$ & $4.0(0.99)$ \\
\hline Self-efficacy for physical activity, mean $(S D)^{c}$ & $4.1(1.0)$ & $4.0(1.0)$ & $4.1(0.97)$ \\
\hline Social support for healthy diet, mean (SD) ${ }^{d}$ & $3.7(0.9)$ & $3.2(0.9)$ & $3.4(0.9)$ \\
\hline Social cohesion, mean $(\mathrm{SD})^{\mathrm{e}}$ & $5.9(0.8)$ & $5.9(1.1)$ & $5.9(1.0)$ \\
\hline Social norms for obesogenic behaviors, mean (SD) ${ }^{d}$ & $2.0(1.0)$ & $2.4(1.1)$ & $2.2(1.1)$ \\
\hline Social norms for weight loss, mean (SD) ${ }^{d}$ & $2.2(0.8)$ & $2.1(0.9)$ & $2.2(0.8)$ \\
\hline \multicolumn{4}{|c|}{ How likely are you to try to lose weight in the next 3 months? No. (\%) } \\
\hline Very unlikely or unlikely & $5(3)$ & $14(9)$ & $19(4)$ \\
\hline Neither likely nor unlikely & $24(13)$ & $33(20)$ & $57(17)$ \\
\hline Very likely or likely & $149(84)$ & $116(71)$ & $265(78)$ \\
\hline
\end{tabular}

${ }^{a}$ Totals vary because of missing data and combined categories. Gender was missing for 4 participants

${ }^{b}$ International Physical Activity Questionnaire [34]

'Reported from a 10-point scale, with 1 being the lowest response option and 10 the highest

${ }^{\mathrm{d}}$ Reported from a 5-point Likert scale, with 1 being the lowest response option and 5 the highest

e Reported from a 7-point Likert scale, with 1 being the lowest response option and 7 the highest

among family and friends. Among participants who were overweight or affected by obesity, social norms favoring weight loss were low (mean [SD], $2.2[0.8]$ ). Social support for healthy diet was high (mean [SD], 3.4 [0.9]). Social cohesion was also high (mean [SD], 5.9 [1.0]). Participants 50 years or older had significantly higher social cohesion $(P=.045)$, lower obesogenic social norms $(P<.001)$, and higher social support $(P=.02)$. There was no significant difference in duration of stay in the United States between participants who were overweight and those who were of normal weight.

\section{Association between weight status of participants and their social networks}

Compared with network members of normal weight, overweight or obese members had more network members who were also overweight or obese (odds ratio [OR], 2.90; 95\% CI, 1.11-7.56; $P=.03$ ). This was most notable for those 50 years or older (OR, 24.23; $95 \% \mathrm{CI}$, $1.55-377.83 ; P=.03)$ and for men (OR, 4.58; $95 \% \mathrm{CI}$, $1.22-17.22 ; P=.02$ ). Overall findings and results by age and sex are shown in Fig. 2.

Those who were affected by obesity also had more overweight network members than those who were overweight, although this was not statistically significant (14.1\% vs $12.4 \%, P=.24)$.

Mediation analysis for association between weight status of participants and their social networks

There were no statistically significant mediation effects between participants who were overweight or affected by obesity and the weight status of their social networks. Overweight and affected by obesity participants had a larger mean (SD) network size than participants with normal weight (5.8 [1.1] vs 5.6 [1.4], $P=.045)$, but network size did not mediate the relationship between the weight status of participants and their social networks.

The correlation between participant BMI and social norms for obesity was small (Pearson correlation -0.13 , $P=.001$ ). Likewise, the correlation between overweight social network members and social norms for obesity was small (Pearson correlation 0.21, $P<.001$ ). However, social norms for obesity did not mediate the total effect of the weight status of the social network members. Similarly, social support and social cohesion did not mediate the relationship between weight status of participants and their social networks.

\section{Association between weight loss intentions among overweight or participants affected by obesity and social network influences}

Of the participants who reported that most or all of their family members and friends were trying to lose weight, $38 \%$ said that they were very likely to lose weight, compared with $17 \%$ of other participants who said that they were very likely to lose weight $(P=.01)$. However, there was no significant difference between groups if "likely" and "very likely" responses were combined ( $83 \%$ vs $80 \%$, $P=.60)$. There was no significant association between weight loss intentions and the number of social contacts trying to lose weight (OR, 1.29; 95\% CI, 0.58-2.85). Overall findings and results by age and sex are shown in Fig. 3. 


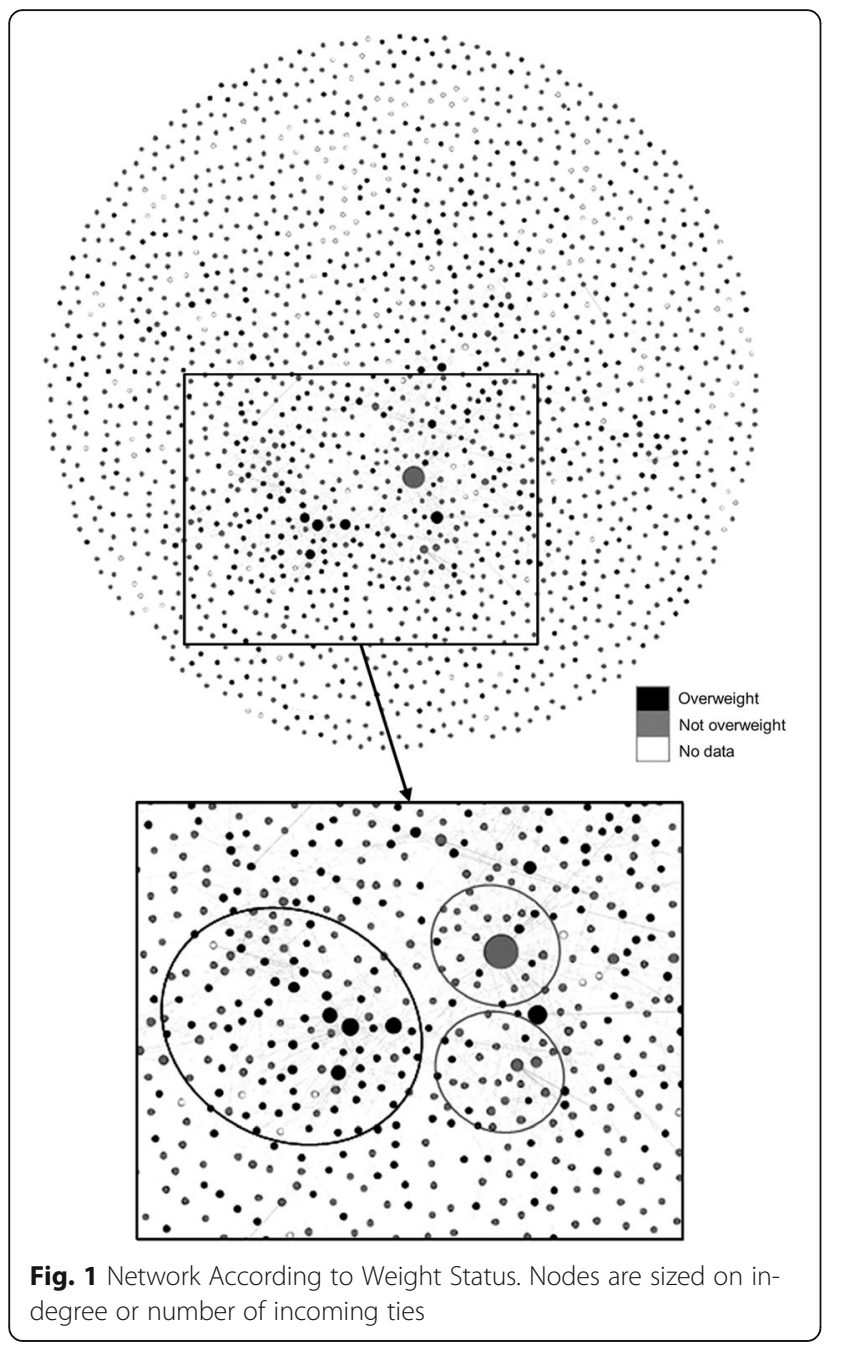

Participants who stated that they were likely or very likely to lose weight, compared with participants who were not likely to lose weight, reported a slightly larger network size (OR, 1.14; $P=.047$ ) and significantly more positive (reenforcing) social norms for weight loss (mean [SD], 2.4 [0.75] vs 1.6 [0.67]; $P<.001$ ); more positive social support for weight loss (mean [SD], 3.4 [0.94] vs 3.1 [0.91]; $P=.004$ ); less favorable obesogenic social norms (mean [SD], 2.0 [1.03] vs 2.6 [0.94]; $P<.001)$; and more social cohesion (mean [SD], 6.0 [0.89] vs $5.7[1.05] ; P=.02$ ).

\section{Mediation analysis for association between weight loss intentions among overweight or participants affected by obesity and social network influences}

There was no statistically significant relationship between participants' likelihood of losing weight and the number of family and friends trying to lose weight; therefore, there were no mediators for this relationship.

The best model for predicting participants' likelihood to lose weight included social norms for weight loss and obesogenic social norms. Network size was not a mediator of weight loss intention.

\section{Association between social contacts trying to lose weight among overweight or Participantsaffected by)besity and social network influences}

Participants who stated that most or all of their social contacts were trying to lose weight, compared with participants whose social contacts were not trying to lose weight, reported more positive social norms for weight loss (mean [SD], 2.9 [0.7] vs 2.1 [0.7]; $P<.001$ ); more positive social support for eating a healthy diet (mean

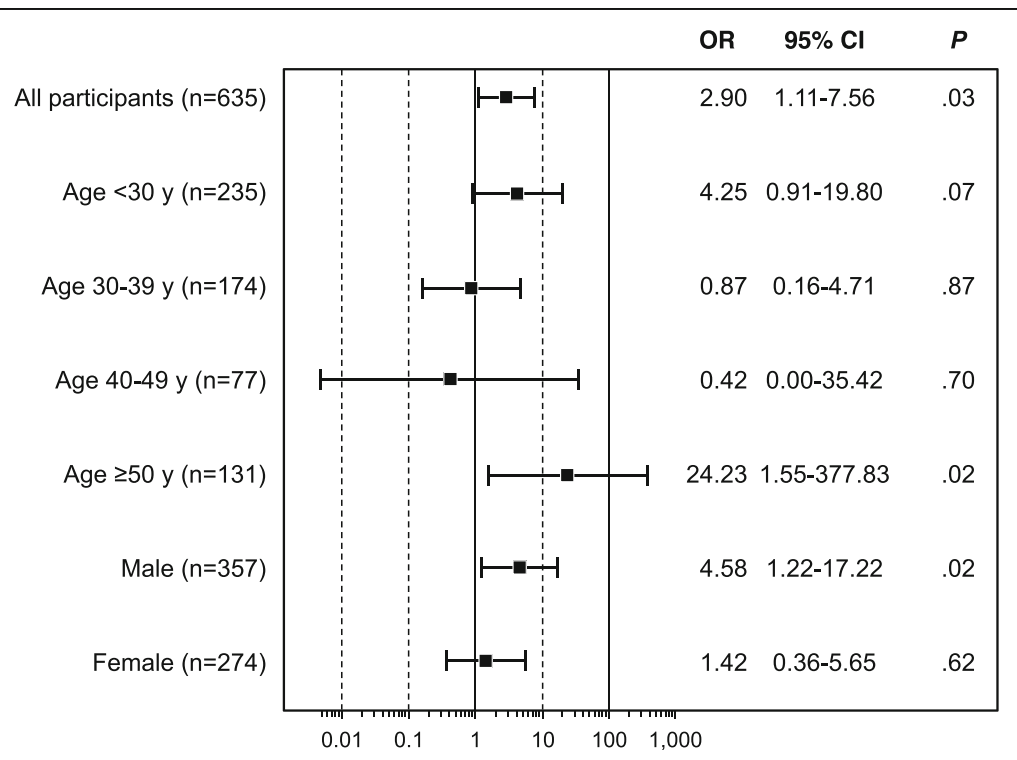

Fig. 2 Association Between Participants Being Overweight or Obese and Number of Overweight Network Members. Age and sex are for all participants. Squares indicate odds ratios (ORs). Error bars indicate $95 \% \mathrm{Cls}$ 


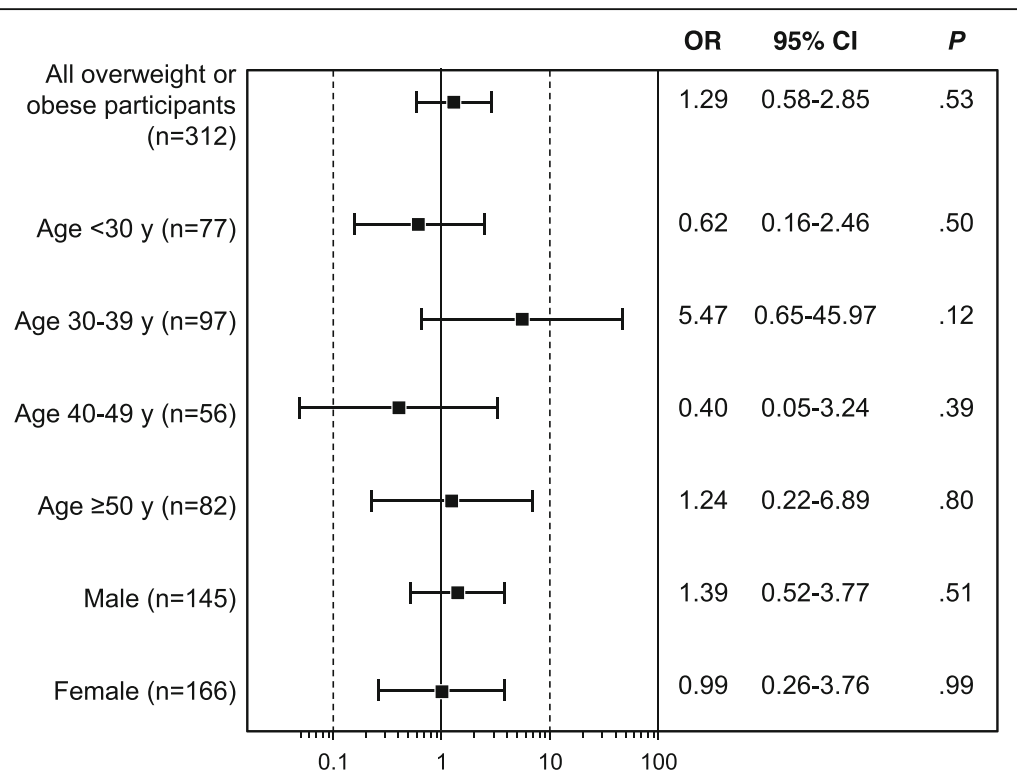

Fig. 3 Association Between Overweight or Obese Participants' Weight Loss Intentions and Network Members' Weight Loss Intentions. Age and sex are for all overweight or participants affected by obesity. Squares indicate odds ratios (ORs). Error bars indicate $95 \% \mathrm{Cls}$

[SD], 3.6 [0.93] vs 3.3 [0.94]; $P=.03)$; and more moderate to high levels of physical activity $(88.0 \%$ vs $70.6 \%$, $P=.003)$.

\section{Discussion}

To our knowledge, this is the first social network analysis study of obesity and related health behaviors among Somali immigrants in the US. Findings from this study indicate that this community has discernible social networks, which are clustered by weight status. The robust and successful recruitment of participants for this study, from a group that has been seen as traditionally difficult for researchers to reach, lends credence to the community-based participatory research approach and holds promise for future intervention work on obesity with the Somali community.

Our study identified clustering of social networks by body weight status, which is consistent with the plurality of studies of general populations [18, 43], thereby extending this association to the Somali immigrant communities in Minnesota. This clustering was most pronounced among men and participants 50 years or older. In the present study, older participants had only slightly smaller networks, had lived in the United States longer, and had significantly higher social cohesion and social support for eating a healthy diet. Previous research showed that older immigrants tend to exhibit lower acculturation than younger groups [44]. Acculturation can be conceived as a multifaceted process of integration on the part of immigrants and their receiving communities [45]. Lower acculturation has been associated with lower rates of obesity and cardiovascular risk among African immigrants [46-48]. Results from our study imply that social cohesion and social support, which are associated with healthy behaviors for obesity $[49,50]$, may be important in weight control among older Somali adults.

Weight loss intention, an important prerequisite for actual weight loss, is positively associated with successful weight loss [51]. In our study, the overweight or participants affected by obesity who reported the highest degree of weight loss intention were the ones who stated that most or all of their family and friends were trying to lose weight. Furthermore, those participants' weight loss intentions were associated with more favorable social norms for weight loss and with higher social support and social cohesion. These findings are consistent with previous studies of general populations that found that weight loss intentions may be influenced by enabling functional network factors, especially social support and social norms for weight loss [52, 53]. At the same time, social support and social norms for weight loss are key factors in facilitating weight loss, and it has been proposed that incorporating them in traditional weight loss interventions may lead to more success $[52,54]$.

In the present study, among participants who were overweight or affected by obesity, an association existed between the number of social contacts trying to lose weight and the social norms for weight loss, social support, and activity level. This finding is consistent with the knowledge that people's behavior may be influenced by social ties and contacts $[52,55]$. Our results extend this finding to the Somali community in Minnesota and imply that these social ties could be harnessed to promote weight loss [56]. Interestingly, among overweight or participants affected by 
obesity, there was no association between the number of social contacts trying to lose weight and social cohesion, which has been associated with health-influencing behaviors among and within groups [57]. This finding may be explained by the low number of social contacts trying to lose weight, especially because weight loss intention was associated with social cohesion, while perception of being physically inactive was inversely associated with social cohesion.

The strengths of the study are that it used a large, community-based sample of a Somali immigrant population. The community-based participatory research approach was key to successful participant recruitment and participation in the study. The study had several limitations: It was confined to 1 city, and thus the results may not be geographically generalizable. The use of perceived weight status for alters was prone to underreporting bias, which likely led to weaker measured associations between weight status and other network characteristics. Likewise, BMI was used as a sole objective classification scheme for assessment of weight class. Finally, the cross-sectional nature of the study and possibility of other unmeasured confounding factors, limits drawing conclusions to associations only and not causality.

\section{Conclusion}

Overall, the findings from this study show that distinct social networks in this community are clustered by weight status and that social contacts and functional network characteristics are related to weight loss intentions. These factors should be considered in weight loss interventions and programs. A social network intervention for weight loss in Somali communities, within a CBPR framework, seems plausible.

\section{Abbreviations}

BMI: Body mass index; CBPR: Community-based participatory research; HIF: Healthy Immigrant Families; IPAQ: International Physical Activity Questionnaire; OR: Odds ratio; RHCP: Rochester Healthy Community Partnership; US: United States

\section{Acknowledgments}

The authors would like to thank all the participants who took part in this study.

\section{Authors' contributions}

MLW, IGS, JWN, and AO developed the study concept and design. JWN led the writing. MKB- $L$ coordinated the study data collection and management YAA, MAN, ON, and AO led data collection efforts, and JMO and PJN analyzed the data. All the authors read and approved the final manuscript.

\section{Funding}

This publication was supported by NIH Grant No. R01 HL 111407 from the National Heart, Lung, and Blood Institute and by CTSA Grant No. UL1 TR000135 from the National Center for Advancing Translational Science (NCATS), and by the Mayo Clinic Office of Health Disparities Research. Its contents are solely the responsibility of the authors and do not necessarily represent the official views of the $\mathrm{NIH}$. The funding bodies had no role in study design; in the collection, analysis, and interpretation of data; writing of the manuscript; and in the decision to submit the manuscript for publication.

\section{Availability of data and materials}

The datasets generated and/or analyzed during the current study are available from the corresponding author on reasonable request.

\section{Ethics approval and consent to participate}

The Mayo Clinic Institutional Review Board approved this study. All participants gave written, signed consent to participate in this study.

\section{Consent for publication}

Not applicable.

\section{Competing interests}

The authors declare that they have no competing interests.

\section{Author details}

${ }^{1}$ Department of Medicine, Mayo Clinic, Rochester, MN, USA. ${ }^{2}$ Research Laboratories, Mayo Clinic, Scottsdale, AZ, USA. ${ }^{3}$ Division of Biomedical Statistics and Informatics, Mayo Clinic, Rochester, MN, USA. ${ }^{4}$ Gastroenterology Research Unit, Mayo Clinic, Rochester, MN, USA. ${ }^{5}$ Somali Community Resettlement Services, Rochester, MN, USA. 'Somalia Rebuild Organization, Rochester, MN, USA

Received: 25 July 2019 Accepted: 3 February 2020

Published online: 17 February 2020

\section{References}

1. Copson RW. Africa's wars and prospects for peace. Armonk (N.Y.); London (GB): M.E. Sharpe; 1994

2. Bradbury M, Healy S. Endless war: a brief history of the Somali conflict. In: Bradbury M, Healy S, editors. Whose peace is it anyway? connecting Somali and international peacemaking, vol. 21: Conciliation Resources; 2010.

3. Yearbook of immigration statistics 2017 [https://www.dhs.gov/immigrationstatistics/yearbook/2017]. Accessed 1 June 2019.

4. Sub-Saharan African immigrants in the United States [https://www. migrationpolicy.org/article/sub-saharan-african-immigrants-united-states]. Accessed 12 Jan 2019.

5. African immigrant population in U.S. steadily climbs [https://www pewresearch.org/fact-tank/2017/02/14/african-immigrant-population-in-u-ssteadily-climbs/]. Accessed 28 May 2018

6. Njeru JW, Hagi-Salaad MF, Haji H, Cha SS, Wieland ML. Diabetes health literacy among Somali patients with diabetes mellitus in a US primary care setting. J Racial Ethn Health Disparities. 2016;3(2):210-6.

7. Njeru JW, Tan EM, St Sauver J, Jacobson DJ, Agunwamba AA, Wilson PM, Rutten LJ, Damodaran S, Wieland ML. High rates of diabetes mellitus, prediabetes and obesity among Somali immigrants and refugees in Minnesota: a retrospective chart review. J Immigr Minor Health. 2016;18(6):1343-9.

8. Koya DL, Egede LE. Association between length of residence and cardiovascular disease risk factors among an ethnically diverse group of United States immigrants. J Gen Intern Med. 2007;22(6):841-6.

9. Singh GK, Siahpush M. All-cause and cause-specific mortality of immigrants and native born in the United States. Am J Public Health. 2001;91(3):392-9.

10. Ahmed $\mathrm{SH}$, Meyer HE, Kjollesdal MK, Madar AA. Prevalence and predictors of overweight and obesity among Somalis in Norway and Somaliland: a comparative study. J Obes. 2018:2018:4539171.

11. Wilhelm AK, Jacobson DJ, Guzman-Corrales L, Fan C, Baker K, Njeru JW, Wieland $\mathrm{ML}$, Boehm DH. Regional variation in diabetic outcomes by country-of-origin and language in an urban safety net hospital. J Community Health. 2016:41(4):798-804

12. Wieland ML, Morrison TB, Cha SS, Rahman AS, Chaudhry R. Diabetes care among Somali immigrants and refugees. J Community Health. 2012;37(3): 680-4.

13. Goel MS, McCarthy EP, Phillips RS, Wee CC. Obesity among US immigrant subgroups by duration of residence. JAMA. 2004;292(23):2860-7.

14. Venters H, Gany F. African immigrant health. J Immigr Minor Health. 2011; 13(2):333-44.

15. Wangdahl J, Lytsy P, Martensson L, Westerling R. Health literacy among refugees in Sweden - a cross-sectional study. BMC Public Health. 2014;14: 1030

16. Pampel FC, Krueger PM, Denney JT. Socioeconomic disparities in health behaviors. Annu Rev Sociol. 2010;36:349-70. 
17. Fletcher A, Bonell C, Sorhaindo A. You are what your friends eat: systematic review of social network analyses of young people's eating behaviours and bodyweight. J Epidemiol Community Health. 2011;65(6):548-55.

18. Christakis NA, Fowler JH. The spread of obesity in a large social network over 32 years. N Engl J Med. 2007;357(4):370-9.

19. Pachucki MA, Jacques PF, Christakis NA. Social network concordance in food choice among spouses, friends, and siblings. Am J Public Health. 2011; 101(11):2170-7.

20. Berkman LF, Glass T, Brissette I, Seeman TE. From social integration to health: Durkheim in the new millennium. Soc Sci Med. 2000;51(6):843-57.

21. Rostila M. Birds of a feather flock together--and fall ill? Migrant homophily and health in Sweden. Sociol Health IIIn. 2010;32(3):382-99.

22. Valente TW. Network interventions. Science. 2012;337(6090):49-53.

23. Latkin CA, Knowlton AR. Social network assessments and interventions for health behavior change: a critical review. Behav Med. 2015:41(3):90-7.

24. Hernández-Plaza S, Alonso-Morillejo E, Pozo-Muñoz C. Social support interventions in migrant populations. Br J Soc Work. 2005;36(7):1151-69.

25. Johnson CE, Ali SA, Shipp MP. Building community-based participatory research partnerships with a Somali refugee community. Am J Prev Med. 2009;37(6 Suppl 1):S230-6.

26. Wallerstein NB, Duran B. Using community-based participatory research to address health disparities. Health Promot Pract. 2006;7(3):312-23.

27. Wieland ML, Weis JA, Yawn BP, Sullivan SM, Millington KL, Smith CM, Bertram S, Nigon JA, Sia IG. Perceptions of tuberculosis among immigrants and refugees at an adult education center: a community-based participatory research approach. J Immigr Minor Health. 2012;14(1):14-22.

28. Wieland ML, Hanza MMM, Weis JA, Meiers SJ, Patten CA, Clark MM, Sloan JA, Novotny PJ, Njeru JW, Abbenyi A, et al. Healthy immigrant families: randomized controlled trial of a family-based nutrition and physical activity intervention. Am J Health Promot. 2018;32(2):473-84.

29. Njeru JW, Patten CA, Hanza MM, Brockman TA, Ridgeway JL, Weis JA, Clark MM, Goodson M, Osman A, Porraz-Capetillo G, et al. Stories for change: development of a diabetes digital storytelling intervention for refugees and immigrants to Minnesota using qualitative methods. BMC Public Health 2015;15:1311.

30. Wieland ML, Nigon JA, Weis JA, Espinda-Brandt L, Beck D, Sia IG. Sustainability of a Tuberculosis Screening Program at an Adult Education Center Through Community-Based Participatory Research. J Public Health Manag Pract. 2019;25(6):602-5. https://doi.org/10.1097/PHH. 0000000000000851. PMID: 30273267.

31. World_Health_Organization. World Health Organization process of translation and adaptation of instruments. 2007. Available from: http://www. who.int/substance_abuse/research_tools/translation/.

32. Formea CM, Mohamed AA, Hassan A, Osman A, Weis JA, Sia IG, Wieland ML. Lessons learned: cultural and linguistic enhancement of surveys through community-based participatory research. Prog Community Health Partnersh. 2014;8(3):331-6.

33. Townsend MS, Kaiser $L L$, Allen LH, Joy AB, Murphy SP. Selecting items for a food behavior checklist for a limited-resource audience. J Nutr Educ Behav. 2003;35(2):69-77.

34. Lee PH, Macfarlane DJ, Lam TH, Stewart SM. Validity of the International Physical Activity Questionnaire Short Form (IPAQ-SF): a systematic review. Int J Behav Nutr Phys Act. 2011:8:115.

35. Leahey TM, Gokee LaRose J, Fava JL, Wing RR. Social influences are associated with BMl and weight loss intentions in young adults. Obesity (Silver Spring). 2011;19(6):1157-62.

36. Gesell SB, Barkin SL, Valente TW. Social network diagnostics: a tool for monitoring group interventions. Implement Sci. 2013;8:116.

37. Sallis JF, Grossman RM, Pinski RB, Patterson TL, Nader PR. The development of scales to measure social support for diet and exercise behaviors. Prev Med. 1987;16(6):825-36.

38. VanderWeele TJ. A unification of mediation and interaction: a 4-way decomposition. Epidemiology. 2014;25(5):749-61

39. StataCorp. Stata statistical software: release 15. College Station: StataCorp LLC; 2017.

40. Borgatti SP, Everett MG, Freeman LC. Ucinet for windows: software for social network analysis. Analytic Technologies: Harvard, MA; 2002.

41. Bastian M, Heymann S, Jacomy M. Gephi: an open source software for exploring and manipulating networks. In: International AAAI Conference on Web and Social Media. Association for the Advancement of Artificial Intelligence; 2009.
42. R Core Team. R: a language and environment for statistical computing. Vienna: R Foundation for Statistical Computing; 2018.

43. Zhang S, de la Haye K, Ji M, An R. Applications of social network analysis to obesity: a systematic review. Obes Rev. 2018;19(7):976-88.

44. Schwartz SJ, Pantin H, Sullivan S, Prado G, Szapocznik J. Nativity and years in the receiving culture as markers of acculturation in ethnic enclaves. J CrossCult Psychol. 2006;37(3):345-53.

45. Schwartz SJ, Unger JB, Zamboanga BL, Szapocznik J. Rethinking the concept of acculturation: implications for theory and research. Am Psychol. 2010; 65(4):237-51.

46. Commodore-Mensah Y, Ukonu N, Obisesan O, Aboagye JK, Agyemang C, Reilly CM, Dunbar SB, Okosun IS. Length of Residence in the United States is Associated With a Higher Prevalence of Cardiometabolic Risk Factors in Immigrants: A Contemporary Analysis of the National Health Interview Survey. J Am Heart Assoc. Assoc. 2016:5(11).

47. Commodore-Mensah Y, Ukonu N, Cooper LA, Agyemang C, Himmelfarb CD. The association between acculturation and cardiovascular disease risk in Ghanaian and Nigerian-born African immigrants in the United States: the afro-cardiac study. J Immigr Minor Health. 2018;20(5):1137-46.

48. Alidu L, Grunfeld EA. A systematic review of acculturation, obesity and health behaviours among migrants to high-income countries. Psychol Health. 2018:33(6):724-45.

49. Berkman LF. Social support, social networks, social cohesion and health. Soc Work Health Care. 2000:31(2):3-14.

50. Chuang YC, Chuang KY, Yang TH. Social cohesion matters in health. Int J Equity Health. 2013;12:87.

51. Schifter DE, Ajzen I. Intention, perceived control, and weight loss: an application of the theory of planned behavior. J Pers Soc Psychol. 1985: 49(3):843-51.

52. Hammond RA. Social influence and obesity. Curr Opin Endocrinol Diabetes Obes. 2010:17(5):467-71.

53. Harmon BE, Forthofer M, Bantum EO, Nigg CR. Perceived influence and college students' diet and physical activity behaviors: an examination of ego-centric social networks. BMC Public Health. 2016;16:473.

54. Nam S, Redeker N, Whittemore R. Social networks and future direction for obesity research: a scoping review. Nurs Outlook. 2015;63(3):299-317.

55. Powell K, Wilcox J, Clonan A, Bissell P, Preston L, Peacock M, Holdsworth M. The role of social networks in the development of overweight and obesity among adults: a scoping review. BMC Public Health. 2015;15:996.

56. Bahr DB, Browning RC, Wyatt HR, Hill JO. Exploiting social networks to mitigate the obesity epidemic. Obesity (Silver Spring). 2009;17(4):723-8.

57. Chin WW, Salisbury WD, Pearson AW, Stollak MJ. Perceived cohesion in small groups adapting and testing the perceived cohesion scale in a smallgroup setting. Small Group Res. 1999:30(6):751-66.

\section{Publisher's Note}

Springer Nature remains neutral with regard to jurisdictional claims in published maps and institutional affiliations.

\section{Ready to submit your research? Choose BMC and benefit from:}

- fast, convenient online submission

- thorough peer review by experienced researchers in your field

- rapid publication on acceptance

- support for research data, including large and complex data types

- gold Open Access which fosters wider collaboration and increased citations

- maximum visibility for your research: over $100 \mathrm{M}$ website views per year

At BMC, research is always in progress.

Learn more biomedcentral.com/submissions 